\title{
ESTADO DA ARTE: HISTÓRIA DA EDUCAÇÃO MUSICAL NOS ANAIS DOS CONGRESSOS NACIONAIS DA ASSOCIAÇÃO BRASILEIRA DE EDUCAÇÃO MUSICAL - ABEM (2003-2015)
}

ESTADO DEL ARTE: HISTORIA DE LA EDUCACIÓN MUSICAL EN LOS ANALES DE LOS CONGRESOS NACIONALES DE LA ASOCIACIÓN BRASILEÑA DE EDUCACIÓN MUSICAL - ABEM (20032015)

STATE OF THE ART: HISTORY OF MUSICAL EDUCATION IN THE ANNALS OF THE NATIONAL CONGRESSES OF THE BRAZILIAN ASSOCIATION OF MUSICAL EDUCATION - ABEM (2003-2015)

Autor 1: Ricardo dos Santos Alencar https://orcid.org/0000-0001-8812-3360 Mestrando em Educação pelo Programa de Pós-Graduação em Educação - PPGED Universidade Federal do Piauí - UFPI Teresina - Piauí - Brasil risantosal@hotmail.com

Autor 2: Ednardo Monteiro Gonzaga do Monti https://orcid.org/0000-0003-3513-3316

Doutor em Educação ProPed/UERJ Professor do Programa de Pós-Graduação em Educação Universidade Federal do Piauí Teresina - Piauí - Brasil ednardomonti@gmail.com

ARTIGO CIENTÍFICO ou RELATO DE EXPERIÊNCIA 


\section{RESUMO}

O presente artigo apresenta o resultado de uma pesquisa do tipo "estado da arte" sobre a História da Educação Musical nos Anais dos Congressos Nacionais e Encontros Anuais da Associação Brasileira de Educação Musical (ABEM). O trabalho baseou-se principalmente nos referenciais teóricos de Norma Ferreira (2002) e Patrícia Oliveira (2018) sobre o estado do conhecimento, e selecionou 25 comunicações por meio da leitura de títulos, resumos e pesquisa das palavras chaves. As comunicações foram organizadas por meio de tabela, contendo o ano de publicação, autoria, título e instituição, agrupados por eixos temáticos (grupos) dispostos em gráficos, contendo o ano e a quantidade de trabalho. Os resultados tomam a História da Educação como um campo de produção de conhecimento a ser explorado, observando aspectos fornecidos pelas temáticas historiográficas protagonizadas, a saber: estudos autobiográficos; ideologias e repertório didático; instituições educativas.

Palavras-Chave: Estado da arte. História da educação musical. Anais. ABEM.

\section{RESUMEN}

Este artículo presenta el resultado de una investigación Del tipo "estado del arte" sobre la Historia de la Educación Musical en los Anales de los Congresos Nacionales y Reuniones Anuales de la Asociación Brasileña de Educación Musical (ABEM). El trabajo se basó principalmente en los marcos teóricos de Norma Ferreira (2002) y Patrícia Oliveira (2018) sobre el estado del conocimiento, y se seleccionaron 25 comunicaciones a través de la lectura de títulos, resúmenes e investigación de palabras clave. Las comunicaciones se organizaron mediante una tabla, conteniendo el año de publicación, autoría, título e institución, agrupadas por ejes temáticos (grupos) dispuestos en gráficos; eue contiene el año y la cantidad de trabajo. Los resultados toman la Historia de la Educación como un campo de producción de conocimiento a ser explorado, observando aspectos aportados por los temas historiográficos protagonistas, a saber: estudios autobiográficos; ideologías y repertorio didáctico; instituciones educacionales.

Palavras Clave: Estado del arte. Historia de la educación musical. Anales. ABEM.

\section{ABSTRACT}

This article presents the result of a type "state of the art" research about the Music Education's History in the Annals of National Congresses and Annual Meetings of the Brazilian Association of Musical Education - ABEM. The work was based mainly on the theoretical frameworks of Norma Ferreira (2002) and Patrícia Oliveira (2018) on the state of knowledge, and selected 25 communications through the reading of titles, abstracts and keyword research. The communications were organized using chart, containing the year of publication, authorship, title and institution, grouped by thematic axes (groups) arranged in graphs; containing the year and the amount of work. The results take the History of Education as a field of knowledge 
ALENCAR, Ricardo dos Santos; MONTI, Ednardo Monteiro Gonzaga do.

“Estado da Arte: História da Educação Musical nos Anais dos Congressos Nacionais da Associação Brasileira de Educação Musical - Abem (2003-2015)" R. Científica UBM - Barra Mansa (RJ), ano XXVI, v. 23, n. 45, 2 . Sem. 2021 p. 01-13. ISSN 1516-4071

productions to be explored, observing aspects provided by the historiographic themes namely: autobiographical studies; ideologies and didactic repertoire; educational institutions.

Keywords: State of the art. History of music education. Annals. ABEM.

\section{INTRODUÇÃO}

O artigo aqui apresentado é fruto de uma pesquisa do tipo "Estado da Arte", que teve como objetivo levantar informações de aspectos qualiquantitativos sobre as publicações que constam nos Anais dos Congressos Nacionais e Encontros Anuais da Associação Brasileira de Educação Musical (ABEM), acerca da História da Educação Musical do Brasil. Os trabalhos foram selecionados por meio da leitura de títulos, resumos e pesquisa de palavras chaves no recorte temporal de 2003 a 2015.

Seguindo as ideias de Romanowski (2006), a investigação do tipo estado da arte contribui para a constituição do campo teórico da História da Educação Musical, pois, conforme a autora, as pesquisas de levantamento possibilitam perceber as ênfases temáticas e os caminhos menos explorados nas comunicações dos congressos. Além disso, entende-se que esses estudos possibilitam o mapeamento da trajetória das disquisições, ao interpretar publicações produzidas sobre a História da Educação Musical, indicando caminhos e fornecendo aporte para reflexões nesse campo.

Segundo Oliveira (2018), devido ao aumento dos programas de pós-graduação e as exigências quantitativas na produção científica, por meio de órgãos de fomento, o número de trabalhos aumentou na área da Educação Musical, entre os anos de 2003 e 2012. Tanto o corpo docente quanto o discente dos cursos de Scrictu sensu são cobrados no que se refere à produção intelectual, em âmbito nacional e internacional. $\mathrm{O}$ mesmo ocorre na perspectiva qualitativa, pois ambas vertentes são utilizadas para pontuar nos programas, o que aumentou significativamente a quantidade e a qualidade da produção.

Por consequência, pesquisas do tipo Estado do conhecimento surgem com preocupação não somente de contabilizar, mas também de analisar as investigações, considerando suas contribuições acadêmicas e a sociedade. Para Norma Ferreira (2002), esse questionamento inicial em "estado da arte" é fundamental. Nas palavras da pesquisadora:

Sustentados e movidos pelo desafio de conhecer o já construído e produzido para depois buscar o que ainda não foi feito, de dedicar cada vez mais atenção a um número considerável de pesquisas realizadas de difícil acesso, de dar conta de determinado saber que se avoluma cada vez mais rapidamente e de divulgá-lo para a sociedade, todos esses pesquisadores trazem em comum a opção metodológica, por se 
ALENCAR, Ricardo dos Santos; MONTI, Ednardo Monteiro Gonzaga do.

“Estado da Arte: História da Educação Musical nos Anais dos Congressos Nacionais da Associação Brasileira de Educação Musical - Abem (2003-2015)" R. Científica UBM - Barra Mansa (RJ), ano XXVI, v. 23, n. 45, 2 . Sem. 2021 p. 01-13. ISSN 1516-4071

constituírem pesquisas de levantamento e de avaliação do conhecimento sobre determinado tema. (FERREIRA, 2002, p. 259)

Ao se adotar tal proposição, este trabalho voltou-se para o "estado da arte", alinhandose também com o escrito de Nair Pires (2013), um levantamento sobre as publicações que abordam a Educação Musical nos catálogos da ABEM. A pesquisa Música nas escolas de educação básica: o estado da arte na produção da Revista da Abem (1992-2011), de Pires (2013), propôs a realização de um mapeamento qualitativo de caráter bibliográfico, tomando como fonte os resumos da produção da Revista da ABEM, elaborados entre 1992 e 2011 . A autora traz indicativos sobre o que foi explorado na pesquisa em educação musical no Segundo Segmento do Ensino Fundamental e Ensino Médio, refletindo sobre como as instituições de ensino superior estão se mobilizando para fazer com que seus profissionais ocupem os lugares destinados aos licenciados em Música. Portanto, a publicação citada acima representa para este trabalho um protótipo metodológico que mobiliza produções acadêmicas pela pesquisa do tipo estado da arte.

Esta investigação foi organizada por meio de uma tabela, contendo o ano e a quantidade de comunicações com o tema História da Educação Musical, selecionadas pela leitura de títulos, resumos e pesquisa das seguintes palavras-chave: História da Educação Musical, Estado da arte, Associação Brasileira de Educação Musical. Adotou-se também para análise quantitativa, gráficos para fins de identificação da incidência de cada temática por ano em cada Congresso e Encontro Anual. Em seguida, os trabalhos foram organizados por tópicos, estabelecendo assim nove grupos para análise; sendo que para este artigo foram selecionadas apenas três.

Assim, o texto está organizado em três seções, alinhavadas pelas temáticas. Na primeira parte, em Estudos (auto) biográficos, os trabalhos agrupados têm como eixo norteador a história de vida de educadores, influências, contexto político. No segundo momento, no tópico Ideologias e Repertório Didático, reuniu-se as comunicações que abordam a prática docente de música sob influência de diferentes manifestações culturais, religiosas e sociais inseridas na prática de repertório. Por último, dedica-se, numa perspectiva histórica às Instituições Educativas de música.

\section{ESTUDOS (AUTO) BIOGRÁFICOS}

Neste eixo temático reuniram-se trabalhos que analisam aspectos históricos do período em que cada biografado viveu, bem como outros elementos que giram em torno da história de vida desses personagens. As comunicações agrupadas neste tópico têm como eixo norteador a 
figura do educador musical, sua vida, influências, contexto político e suas conexões com a música. Dessa forma, ainda que os objetos das pesquisas- como materiais didáticos, ideologias e atitudes- possam perpassar as comunicações desta temática, as análises se centram nas vidas dos educadores, considerando suas visões de mundo frente aos desafios encontrados na prática da educação musical. Neste item de análise, a maior parte das fontes das pesquisas foi obtida por meio de livros, cadernos, partituras, diários, impressos da época, além de relatos de descendentes e pessoas que tiveram contato direto e indireto com os docentes.

A comunicação “José Siqueira, o educador”, de Josélia Ramalho Vieira (2006), discute a obra do compositor biografado. Dialoga com materiais pedagógicos adotados pelo maestro, tais como: livros, composições e partituras utilizados na sua prática de ensino de música num cenário erudito. A autora dessa publicação sugere que o educador José Siqueira seja mais estudado, pois acredita que sua obra represente, assim como sua trajetória, um significativo acervo didático para a educação musical do país. O texto traz também uma abordagem da obra do compositor através da Suíte sertaneja (baião, aboio e coco de engenho) para violoncelo e piano, composta em 1948.

Já "O canto orfeônico na Paraíba", de Luceni Caetano da Silva (2006) discute a estreita relação do canto orfeônico do estado da Paraíba com o canto orfeônico do Rio de Janeiro. A pesquisadora aborda a trajetória de Gazzi de Sá, que a convite de Villa-Lobos aceitou atuar no Conservatório Nacional de Canto Orfeônico - RJ, entre 1930 e 1940; e o posterior empenho do músico nordestino em criar um Conservatório de Canto Orfeônico na Paraíba. Partindo deste ponto, esta comunicação discute o relevante papel do educador nordestino na história da educação musical da Paraíba, destacando o singular prazer que o biografado tinha ao exercer a docência, ainda que sob as orientações de Villa-Lobos e inserido num contexto político rigoroso.

O terceiro trabalho desta temática é "Professores de música pioneiros na educação musical escolar do distrito federal: fontes documentais e análise interpretativa", de Clarisse Cabral (2015). É uma publicação do GT (Grupo de Trabalho) 1.3, História da Educação Musical - 2015, do XXII Congresso Anual da Associação Brasileira de Educação Musical. ${ }^{1}$ O texto acima apresenta o recorte de uma pesquisa de iniciação científica, à época em andamento, que

${ }^{1}$ Esse grupo de trabalho nasceu de uma proposta apresentada na Assembleia Geral Ordinária da ABEM, realizada durante seu congresso anual, em 2011, na cidade de Vitória (ES). Entretanto, somente em 2015, no XXII Congresso Nacional, é que aconteceram as primeiras sessões do Grupo de Trabalho História da Educação Musical. 
discutia a atuação de três professoras de música na educação básica de Brasília. A pesquisa reuniu fontes de pesquisa arquivadas no Museu da Educação da UnB, protagonizando registros de entrevistas; ou seja, narrativas autobiográficas das professoras Maria de Sousa Almeida, Maria de Lourdes Cruvinel Brandão e Neuza França. Como resultado, este trabalho sugere concepções de ensino, visões epistemológicas e princípios em educação musical, que contribuíram com o ensino de música do Distrito Federal, fazendo desta pesquisa uma fonte historiográfica para mais investigações.

O quarto trabalho selecionado é de Frederico Silva Santos (2015) e tem como título "Leopoldo Miguéz: compositor, diretor e educador musical nos primeiros anos da República". O objetivo principal da comunicação é evidenciar a trajetória de Leopoldo Miguéz na História da Educação Musical no Brasil, observando sua ideologia e seus projetos, tendo como aporte metodológico a revisão de literatura e a pesquisa documental. Trata-se de uma das poucas pesquisas sobre o músico com foco na educação, pois, segundo Frederico Silva Santos, somente o olhar atento da história seria capaz de revelar uma versão não unilateral do compositor Leopoldo Miguéz; isto é, trazer para o conhecimento do público um Miguéz muito além de sua obra sinfônica, um músico que angariou para si o trabalho de "musicalizar" uma nação, seja através de sua produção intelectual ou administrativa.

O quinto e último trabalho deste agrupamento analisa a relevância de Heitor VillaLobos, bem como do canto orfeônico na história da educação musical brasileira, pois delimita, através de uma revisão literária multidisciplinar o caminho percorrido, até então, pelo ensino da música na história da educação do Brasil. É a comunicação "A prática coral e a educação musical”, de Rogéria Tatiane Soares Franchini (2015), também do G.T. 1.3, do XXII Congresso Anual da ABEM - 2015. Nessa pesquisa, considera-se como foco principal a biografia de VillaLobos. Ao dividir o trabalho em duas partes, a pesquisadora discorre primeiro sobre a história da educação brasileira, explanando os benefícios do canto coral, tais como a capacidade de desenvolver habilidades cognitivas e aspectos emocionais-sociais. Em seguida, analisa o Canto Orfeônico numa perspectiva histórica, sobre o direcionamento patriótico e ideológico de Heitor Villa-Lobos, verificando em seu projeto de educação musical aspectos extramusicais que visavam, além do ensino de música, formar gerações de "bons" sentimentos estéticos e cívicos.

Assim, nos trabalhos da perspectiva (auto) biográfica é possível perceber como o arcabouço historiográfico foi significativo na coleta de dados para o entendimento das práticas educativas de cada professor de música pesquisado. Logo, ainda que o objeto de estudo seja a vida de alguém, neste agrupamento, percebe-se como a história da educação musical permite 
ao pesquisador enveredar por vias não pensadas nas hipóteses iniciais; isto é, caminhar por temáticas relevantes, como recursos didáticos e pedagógicos do ensino da música, instituição de acervos, as relações públicas e políticas dos pesquisados, além da importância das próprias figuras dos biografados.

\section{IDEOLOGIAS E REPERTÓRIO DIDÁTICO}

Neste tópico estão os estudos que discutem historicamente as condições sociais e políticas difundidas por repertórios musicais, explorando também os objetivos doutrinários religiosos e ideológicos de obras dessa expressão artística. Em outras palavras, agruparam-se as comunicações que abordam a história da educação musical em diferentes manifestações culturais, religiosas e sociais inseridas na prática de repertório.

Nessa perspectiva, encontramos o que Bourdieu (2001) chama de "rede cruzada de limitações", que envolvem sujeitos dominantes e dominados por meio de uma complexa estrutura de ações que se entrelaçam e estabelecem uma relação de poder. Ao considerar a cultura como essa complexa e volátil estrutura, é possível entender a educação musical como um instrumento de tecer, que serve aos interesses a que se sujeita; ou seja, uma intenção, por vezes até mais valorizada do que a própria música. Partindo dessas ideias, compreende-se que transmitir e difundir um repertório musical vinculado às danças tradicionais, práticas religiosas, vertentes ideológicas e aos ideais partidários assumem o protagonismo nesta categoria, dentro da história da educação musical.

A primeira comunicação está nos anais do XV Congresso Anual da ABEM, realizado em João Pessoa, ocorrido entre 17 e 20 de outubro de 2006. De Luciane Wilke Freitas Garbosa (2006), o trabalho "Educação musical nas escolas de imigrantes alemães: uma análise a partir de manuais escolares de música" relata reflexões dos cancioneiros "Es tönen die Lieder... e Kommt und singet”, na história da educação musical do Rio Grande do Sul, na década de 1930. Também discorre sobre a identidade híbrida refletida nas tradições culturais alemã e brasileira, transmitidas através do ensino de música. Esse repertório, através das canções da cultura alemã, valoriza a língua de origem desse povo no país que acolheu seus que descendentes, o Brasil.

A seguinte comunicação é do G.T 1.3, XXII Congresso Anual da ABEM - 2015, de Cássia Neivert e Regiana Balnk Wille (2015). O trabalho “A Influência de Martinho Lutero na Educação Musical" analisa a influência produção de Martinho Lutero no ensino de música no Brasil e na ocasião desse congresso acadêmico, a pesquisa encontrava-se na fase de coleta de 
dados. As autoras desse artigo sinalizam como marco decisivo a descentralização do ensino desta linguagem artística, que era monopolizada pela igreja católica, e analisam como as ideias luteranas trouxeram ao século XVI condições para as pessoas estudarem música.

Na comunicação "Educação Musical e Formação Política no movimento operário: Rio de Janeiro e São Paulo, 1906-1921”, de Gabriel Otoni Calhau Martins (2015), o repertório musical é analisado historicamente como elemento de formação social do movimento anarquista do início do século XX nas duas capitais. É mais uma comunicação do GT 1.3 do XXII Congresso Anual da ABEM - 2015. O texto em questão descreve uma educação musical que girava em torno das orquestras formadas dentro dos movimentos anarquistas, principalmente, com o intuito de ensinar a tocar os hinos de lutas sociais. Isso porque esses grupos musicais eram formados por leigos e daí se fazia necessária a prática do ensino específico dessa expressão artística. O autor pontua também a questão de que, nesse período, poucas pessoas tinham acesso ao ensino de música, bem como de outras práticas culturais. A publicação sinaliza que essa relação música e grupos anarquistas possibilitava uma via de mão dupla, na medida em que a música fazia uso da oportunidade para o seu ensino e os movimentos utilizavam-se da música para pregar seus ideais.

Como resultado, percebeu-se que o repertório musical tanto é influenciador quanto influenciado diretamente pelas questões sociais e pela cultura, e aponta a música como fomentadora ideológica que abre espaços em ambientes escolares, ou onde dela se utilizarem. Como sinaliza Martins (2015), limitador é o entendimento de que lugar de estudar é somente nos espaços escolares. Sendo assim, observou-se que a educação musical não acontece somente nos lugares destinados para o ensino, mas em todo o contexto histórico e cultural que a arte está inserida, considerando todas as funções sociais exercidas por esta.

\section{INSTITUIÇÕES EDUCATIVAS}

Neste tópico, agruparam-se trabalhos que têm em comum a história das instituições de ensino de música, observando aspectos como a concepção que se tem a respeito do professor dessa linguagem artística, o levantamento de acervos historiográficos da prática de ensino e os recursos pedagógicos que os docentes têm no cotidiano. A temática aborda também os avanços dos chamados "cursos livres"; ou seja, do ensino não formal, tais como fomento à pesquisa em música e propostas didáticas, por meio do Curso Internacional de Férias Pro Arte de Teresópolis 
- RJ. Assim, para melhor compreensão, este grupo se organizará em dois domínios para análise: história de ensino formal e história de ensino não formal.

Portanto, neste primeiro momento desta temática, analisa-se o domínio histórias de ensino formal, que possui como locus a educação básica. O primeiro texto é "Construção da Educação Musical Escolar no Distrito Federal”, de Delmary Vasconcelos de Abreu (2013), publicado no XXI Congresso Nacional da ABEM. Essa pesquisa teve como principal objetivo entender a forma como a Secretaria de Estado e Educação do Distrito Federal (SEE/DF) idealiza o professor de música da educação básica e, como de fato, se encontra a realidade desse docente. Para tanto, a autora propôs uma interpretação dos caminhos percorridos em relação à concepção que as escolas de Brasília têm em relação ao ensino de música. Há também a análise do processo histórico envolvendo a legislação que estabelece a obrigatoriedade desse ensino. Delmary considera também histórias de professores e gestores da educação com suas experiências práticas, apresentando aspectos sociais, biográficos e culturais que moldam a representatividade às práticas educativas musicais. O estudo teve como objetivo principal investigar a forma como o ensino de música foi construído historicamente na Capital do país, visando uma proposta pedagógica, pois Abreu (2013) fazia parte de um grupo de trabalho da Secretaria do Estado da Educação que discutia a formulação do currículo de música na educação formal de Brasília.

A segunda comunicação deste domínio, ainda no ensino formal, é "Professores de música pioneiros na educação musical escolar do Distrito Federal: um levantamento de fontes documentais", de Ester Elke Costa Macedo (2015). Do GT 1.3, História da Educação Musical, do XXII Congresso Anual da ABEM - 2015, o trabalho tem como base o Museu da Educação do Distrito Federal, lugar de memória no qual os esforços se voltaram para a coleta de dados, onde os pesquisadores se esforçaram para produzir elementos, em uma ação da Secretaria de Educação, no intuito de organizar acervos institucionais visando análises sobre o ensino de música na capital do país.

Já no segundo domínio, histórias de ensino não formal estão duas produções. O primeiro texto data de 2010 e foi publicado no XIX Congresso Anual da Associação Brasileira de Educação Musical. A comunicação "Curso Internacional de Férias Pro Arte de Teresópolis (1950 a 1989): seu processo educativo-musical", de José Nunes Fernandes e Denise Carvalho de Figueiredo (2010), apresenta o registro de um momento significativo para a história da educação musical do Brasil, almejando a identificação e contextualização do processo educativo que gerou o Curso Internacional de Férias Pro Arte de Teresópolis (CIFT). De caráter 
descritivo, a pesquisa se desenvolvia (à época, ainda em andamento) através de consulta aos documentos do acervo da PRO ARTE (Feso/Teresópolis) e entrevistas. Essa concentração de fontes é indicada pelo estudo como manancial abundante de registros para pesquisas, considerando os anos em que o curso ocorreu (1950 a 1989), tais como partituras, artigos de jornais, livros, métodos de ensino, cartas.

A outra comunicação selecionada sobre o ensino em intuição não formal é "O ensino de música em cursos e festivais de férias: o caso do Curso Internacional de Férias Pro Arte de Teresópolis (1950 a 1989) - sua origem, seu pioneirismo e seu nível”, também de Fernandes e Figueiredo (2010). Um trabalho que foi publicado no XIX Congresso Anual da ABEM, e teve como objetivo o registro de informações históricas acerca da origem do Curso Internacional de Férias Pro Arte de Teresópolis - CIFT. O trabalho configura-se também como uma fonte que, somada a vários registros da Pro Arte Sociedade de Artes, Letras e Ciências - idealizadora do projeto, atestam a existência do curso e a ação histórico-musical que formou professores de música e músicos de significativo nível performático.

Essa temática representa também o desbravamento dos cursos livres de música e a importância da pesquisa historiográfica, no que tange à herança do caráter pioneiro destas iniciativas, ao mesmo tempo em que apura o nosso olhar para a História. Para Rocha e Garcia, este tipo de trabalho histórico:

\footnotetext{
Nos possibilita pensar, em termos específicos, sobre a importância que a apreciação crítica do passado, proposto pela História, pode exercer no desenvolvimento das próprias práticas de ensino e de aprendizagem musicais, sobretudo, em um país com tamanha diversidade sociocultural. (ROCHA; GARCIA, 2016, p. 117)
}

O fato é que neste levantamento, tanto as pesquisas de fontes bibliográficas, quanto as de fontes empíricas apresentaram-se como uma busca na História da Educação para entender o caminho percorrido pela educação musical. Assim, é possível refletir sobre o passado e contemplar o legado das práticas educativas que o compõem, as perspectivas e os desafios do ensino de música, de maneira a fomentar o interesse pela pesquisa em História da Educação Musical, voltando-se a esta não somente como uma referência, mas como um campo específico no qual é possível encontrar e formular vários objetos de estudo.

\section{CONSIDERAÇÕES FINAIS}

As produções do eixo temático Estudos (auto) biográficos apresentaram a maior quantidade de trabalhos, totalizando cinco, e apontam à importância da trajetória dos 
educadores musicais e o legado que esses docentes deixaram, mediante suas iniciativas desbravadoras para dar aulas.

O grupo temático Ideologias e Repertório Didático reuniu duas publicações. Por se tratar de um assunto que envolve aspectos culturais, sociais e religiosos, ou seja, conteúdo que provavelmente está presente em todas as manifestações culturais que se utilizam da música. Acredita-se que o tema pode ser mais estudado, dada a diversidade cultural do nosso país e a riqueza das práticas de ensino dessa manifestação artística. Portanto, partindo do princípio de que a música é um componente da cultura, impregnada de práticas sociais e de intenções doutrinárias, o ensino dessa linguagem torna-se estimulante para as práticas cognitivas nos ambientes que a têm como instrumento de disseminação de um saber específico. Portanto, por meio do repertório didático, essa arte se serve das práticas ideológicas, ao mesmo tempo em que os grupos a utilizam para transmitir suas ideias, reforçando o conceito de que a educação musical acontece não somente nos espaços destinados a ela, mas em todo o contexto histórico em que essa expressão está inserida.

Na temática Instituições Educativas, agruparam-se quatro estudos que apresentaram em comum a intenção de levantar informações a respeito das práticas de ensino de música, visando à proposta pedagógica, organizando acervos dessas práticas de ensino e analisando a concepção que se tem a respeito do professor de música na educação básica. O trabalho destaca também a atuação dos "cursos livres", apresentando acervo do PRO ARTE (Feso/Teresópolis), que atuou por mais de 35 anos no fomento de pesquisas, produção de materiais didáticos, cursos de capacitação, por meio de uma ação que formou professores de música e músicos de significativo nível performático. Neste agrupamento também ficou clara a importância das pesquisas historiográficas, principalmente para o confronto com as fontes empíricas.

Por fim, ao analisar as comunicações dos Anais de Congressos e dos Encontros Anuais da Associação Brasileira de Educação Musical (ABEM), por meio destes três eixos temáticos, o presente trabalho sugere diagnósticos indicativos de trajetórias do ensino de música, dentre muitas outras, para refletir sobre o passado, como também para apontar caminhos em direção ao avanço. Além disso, considerando esse conjunto de estudos acadêmicos, pode-se sinalizar demandas para pesquisadores da área da educação musical e auxiliá-los na identificação da relevância de suas próprias investigações para a comunidade científica.

\section{REFERÊNCIAS}


ALENCAR, Ricardo dos Santos; MONTI, Ednardo Monteiro Gonzaga do.

“Estado da Arte: História da Educação Musical nos Anais dos Congressos Nacionais da Associação Brasileira de Educação Musical - Abem (2003-2015) " R. Científica UBM - Barra Mansa (RJ), ano XXVI, v. 23, n. 45, 2 . Sem. 2021 p. 01-13. ISSN 1516-4071

ABREU, Delmary Vasconcelos de. Construção da Educação Musical Escolar no Distrito Federal. In: CONGRESSO NACIONAL DA ASSOCIAÇÃO BRASILEIRA DE EDUCAÇÃ̃ MUSICAL, 21., 2013, Pirenópolis. Anais.... Pirenópolis: Abem, 2013. p. 690 703. Disponível em: <http://abemeducacaomusical.com.br/anais_abem.asp>. Acesso em: 07 ago. 2017.

BOURDIEU, Pierre. Razões Práticas: sobre a teoria da ação. Campinas: Papirus, 2001.

CABRAL, Clarice. Professores de música pioneiros na educação musical escolar do Distrito Federal: fontes documentais e análise interpretativa. In: CONGRESSO NACIONAL DA ASSOCIAÇÃO BRASILEIRA DE EDUCAÇÃO MUSICAL, 22., 2015, Natal. Anais.... Natal: Abem, 2015. p. 1 - 9. Disponível em:

<http://abemeducacaomusical.com.br/anais_congresso/v2/index.html>. Acesso em: 10 ago. 2017.

FERNANDES, José Nunes; FIGUEIREDO, Denise Carvalho de. Curso Internacional de Férias Pro Arte de Teresópolis (1950 a 1989): seu processo educativo-musical. In: CONGRESSO NACIONAL DA ASSOCIAÇÃO BRASILEIRA DE EDUCAÇÃO MUSICAL, 19., 2010, Goiânia. Anais.... Goiânia: Abem, 2010. p. 626 - 641. Disponível em: <http://abemeducacaomusical.com.br/anais_abem.asp>. Acesso em: 07 ago. 2017.

FERREIRA, Norma Sandra de Almeida. As pesquisas denominadas "estado da arte". Educação e Sociedade, São Paulo, v. 23, n. 79, p.257-272, ago. 2002.

FRANCHINI, Rogéria Tatiane Soares. A prática coral e a educação musical. In: CONGRESSO NACIONAL DA ABEM, XXII. 2015. Anais [...] Natal: ABEM, 2015. 1-12 p. Disponível em:

$<$ http://abemeducacaomusical.com.br/conferencias/index.php/xxiicongresso/schedConf/prese ntations>. Acesso em: 9 mar. 2021.

GARBOSA, Luciane Wilke Freitas. Educação musical nas escolas de imigrantes alemães: uma análise a partir de manuais escolares de música. In: ENCONTRO ANUAL DA ABEM, 15., 2006, João Pessoa. Anais.... João Pessoa: Abem, 2006. p. 301 - 310. Disponível em: <http://abemeducacaomusical.com.br/anais_abem.asp>. Acesso em: 05 ago. 2017.

MACEDO, Ester Elke Costa. Professores de música pioneiros na educação musical escolar do Distrito Federal: um levantamento de fontes documentais. In: CONGRESSO NACIONAL DA ASSOCIAÇÃ̃O BRASILEIRA DE EDUCAÇÃO MUSICAL, 22., 2015, Natal. Anais.... Natal: Abem, 2015. p. 1 - 9. Disponível em:

$<$ http://abemeducacaomusical.com.br/anais_congresso/v2/index.html >. Acesso em: 10 ago. 2017.

MARQUES, Marila Cristine Sales. O Ensino da Música nas Escolas Particulares da Rede de Ensino Fundamental de Salvador. In: CONGRESSO NACIONAL DA ASSOCIAÇÃO BRASILEIRA DE EDUCAÇÃO MUSICAL, 19., 2010, Goiânia. Anais.... Goiânia: Abem, 2010. p. 1444 - 1454. Disponível em: 〈http://abemeducacaomusical.com.br/anais_abem.asp>. Acesso em: 07 ago. 2017.

MARTINS, Gabriel Otoni Calhau. Educação Musical e Formação Política no movimento operário: Rio de Janeiro e São Paulo, 1906-1921. In: CONGRESSO NACIONAL DA 
ASSOCIAÇÃO BRASILEIRA DE EDUCAÇÃO MUSICAL, 22., 2015, Natal. Anais.... Natal: Abem, 2015. p. 1 - 9. Disponível em:

<http://abemeducacaomusical.com.br/anais_congresso/v2/index.html>. Acesso em: 10 ago. 2017.

NEIVERT, Cássia; WILLE, Blank Regiana. A Influência de Martinho Lutero na Educação Musical. In: CONGRESSO ANUAL DA ABEM, 22., 2015, Natal. Anais.... Natal: Abem, 2015. p. 1 - 10. Disponível em:

<http://abemeducacaomusical.com.br/anais_congresso/v2/index.html>. Acesso em: 10 ago. 2017.

OLIVEIRA, Patrícia Lakchmi Leite Mertzig Gonçalves de. PESQUISAS EM EDUCAÇÃO MUSICAL A DISTÂNCIA NO BRASIL: MAPEAMENTO DE TESES E

DISSERTAÇÕES (2002 - 2015). 2018. 230 f. Tese (Doutorado) - Curso de Programa de Pós-Graduação em Educação, Universidade Estadual de Maringá, Maringá, 2018.

PIRES, Nair; DALBEN, Ângela Imaculada Loureiro de Freitas. Música nas escolas de educação básica: o estado da arte na produção da Revista da Abem (1992-2011). Revista da Abem, Londrina, v. 21, n. 30, p.103-118, jun. 2013.

ROCHA, Inês de Almeida; GARCIA, Gilberto Vieira. História da Educação Musical no Brasil: reflexões sobre a primeira edição do GT 1.3 - XXII Congresso da ABEM (2015). Revista da Abem, Londrina, v. 24, n. 37, p.114-126, jun. 2016 ENCONTRO ANUAL DA ABEM, 15., 2006, João Pessoa. Educação musical: produção científica, formação profissional, políticas públicas e impactos sociais. João Pessoa: UFPB, 2006. p. 834.

ROMANOWSKI, Joana Paulin; TEODORA, Romilda. AS PESQUISAS DENOMINADAS DO TIPO “ESTADO DA ARTE”" EM EDUCAÇÃO. Diálogo Educ., Curitiba, v. 6, n. 19, p.37-50, dez. 2006.

SANTOS, Frederico Silva. Leopoldo Miguéz: compositor, diretor e educador musical nos primeiros anos da República. In: CONGRESSO NACIONAL DA ASSOCIAÇÃO BRASILEIRA DE EDUCAÇÃO MUSICAL, 22., 2015, Natal. Anais.... Natal: Abem, 2015. p. 1 - 8. Disponível em:

<http://abemeducacaomusical.com.br/anais_congresso/v2/index.html>. Acesso em: 10 ago. 2017.

SILVA, Francisca Jocineide da Costa e; CARVALHO, Maria Eulina Pessoa de. O ESTADO DA ARTE DAS PESQUISAS EDUCACIONAIS SOBRE GÊNERO E EDUCAÇÃO INFANTIL: uma introdução. In: REDOR, 18., 2014, Recife. Ensaio. Recife: Ufpb, 2014. p. 1 $-17$.

SILVA, Luceni Caetano da. Os contos do canto orfeônico na Paraíba. In: ENCONTRO ANUAL DA ABEM, 15., 2006, João Pessoa. Anais.... João Pessoa: Abem, 2006. p. 588 597. Disponível em: <http://abemeducacaomusical.com.br/anais_abem.asp>. Acesso em: 05 ago. 2017.

VIEIRA, Josélia Ramalho; ENCONTRO ANUAL DA ABEM, 15., 2006, João Pessoa. José Siqueira, o educador. João Pessoa: Abem, 2006. 7 p. 